\title{
Inevitable aging and the resultant mental disorders in developing countries: a Sociological appraisal
}

Mohammad Taghi Sheykhi,

Professor Emeritus of Sociology, Alzahra University, Tehran, Iran

Corresponding author: Mohammad Taghi Sheykhi, Professor Emeritus of Sociology, Alzahra University, Tehran, Iran

Received date: January 02, 2020; Accepted date: January 15, 2020; Published date: January $25,2020$.

Citation: Mohammad Taghi Sheykhi, (2020) Inevitable aging and the resultant mental disorders In developing countries: a sociological appraisal. J Clinical Research and Clinical Trials. 2(1); DOI: 10.31579/2693-4779/002

Copyright: () 2020. Mohammad Taghi Sheykhi. This is an open-access article distributed under the terms of the Creative Commons Attribution License, which permits unrestricted use, distribution, and reproduction in any medium, provided the original author and source are credited.

\section{Abstract}

Aging is inevitably associated with a large number of body functions including the mental health. In addition to that, heart function, emotions, moods etc. could be mentioned as the results of gradual aging. Such conditions are usually accompanied with increase in medications consumption and decline in quality of life. Though usually medical sciences study mental health conditions, sociology also needs to be applied to appraise the "cause and effect" of mental health. As life expectancy is globally increasing, more and more people are subject to mental disorders, Alzheimer's disorders, dementia, depression and many more, as the effects of aging extensively impact mental health. Therefore, under the conditions of rapid aging, geriatrics needs to be strengthened and improved as much as possible to safeguard mental health. However, structural changes in terms of biological, physical, psychological and chemical reactions which inevitably occur with aging, need prevention and appropriate medication, and other investments in long term, and if not, other vulnerabilities will inevitably appear.

Keywords: aging; mental health; quality of life; structural change; alzheimer's disorders

\section{Objective}

Aging is a major risk factor for the body as a whole. It affects various parts of body with special reference to mental health. Though medical sciences usually touch it, and study the functionality of mental health, sociology as well needs to appraise mental health of human bodies throughout life span. Human beings once had an average age almost like chimpanzees around 15 years. Science and technology have highly

contributed to the increase of average age of human's --expanding it to 84 years for babies being born in recent years in Japan. Life expectancy of humans being increased to 46 years in Sierra Leon and 84 years in Japan has left behind increasing issues including Parkinson's, Dementia and Alzheimer's disorders for different classes of people. While aging is on the way, social change is in different dimensions continuing; large and extended families are breaking into smaller and nuclear families in which care giving to the aging people with disorders becomes rare and in many cases impossible. That is why social nursing and social work services must increase and improve. Developing countries though usually economically poor, but at the same time facing population aging; are in hard time with their aging people, and their mental disorders. Such countries need to invest more on their medical and social services to manage their mentally aging patients.

The aim of the present research is to represent the role of social accounting as an umbrella including demographic, social, cultural and environmental indicators/variables which bring about healthy state of life in developing countries. In the meantime, efficient management would be possible and attainable under the conditions of aging in any country. While the three social, cultural and environmental variables are a triangle being faced by the developing countries today, the quality and quantity of population also play an important and determining role, and shortage of which contributes to socio-economic vulnerabilities, mental health deficiency among a large number of people in those countries. The aforementioned variables have also a pivotal role in accessing a healthy economic system. However, aging can be defined as the

combination of biological, psychological, and social processes that affect people as they grow older $[1,2,3]$.

\section{Population Growth vs Healthy Aging}

Socio-mental health can play a determining role in population planning. Population growth rate has largely affected population structure in recent decades in the developing countries; a phenomenon leading to young population structure. While about $83 \%$ of the world population is residing in the developing world [4], Socio-mental health is largely associated with it, and that has resulted in increasing social abnormalities forthose countries, leaving behind illness, poverty, unbridled abnormalities, increasing deviances, increasing drug abuse etc. The current situation has caused $28 \%$ of population in the developing world remaining below 15 years of age. Such a scenario will encounter the countries of the developing world with a large bulk of unemployed youth in search of food and jobs in the years to come. However, the current situation is leading many developing countries to delayed marriages culminating in lower fertility rate within the youth of 
below 35 years of age [5]. Because of failures of social accounting, many developing countries are surprisingly facing young populations whom cannot be easily fed and employed in their young age. Appropriate actions must usually be notified through social accounting, and that includes economic and industrial investments versus those newly born. Under such circumstances many of those born in 1980s and beyond are in poverty conditions in developing world. The scenario means that there is not economic independence and hiring opportunities for such people. The present circumstances as a motivation, moves the youth towards antisocial behaviors. Though the family institution in some countries like Iran tries to support such young unemployed youth, yet they are pulled toward drug addiction that eventually pushes them towards mental deficiency.

Therefore, to modify the existing situation, and control its continuity for the years to come, population growth rate must be checked, and a coordination between population growth rate and creation of job opportunities need to be maintained. If that is not practiced, the current youth should expect further deviations in the future. According to a socioeconomic and demographic view, for every $1 \%$ of population growth, there should be $4 \%$ economic growth. Such a balance helps in not having later mental deficiency and other dilemmas [6]

Though some developing countries have had declining population growth rates in recent years, yet the volume of young population has remained the same, and even some added to it (15+) every year. These youth potentially vulnerable, seriously need social accounting to be less jeopardizing the economy and later mental health. However, an increasing number of the Third World countries are facing such a scenario.

Thus, to reach a healthy economy and mental health, the aforementioned destructive factors must be controlled, and eliminated. It must also be notified that the culture of drug deals could not be rooted out overnight. Sociologically speaking, social accounting based on the current parameters would be a turning point to reach a healthy aging and mental health with food accessibility. It is worth mentioning that along with the population policies, minding gerontology, and other cultural, social and environmental policies should be considered. Such a strategy could eventually help in attaining a healthy aging to operate. However, the idea of separation of older people from active roles in society is somehow normal and appropriate, and benefits both society and older individuals (Stuart Hamilton, ISBN 184910-426-1).

Though for most of human history the average life expectancy at birth was less 20 years because of increasing death rate in infancy and early childhood, it increased to 47 in the United States for those born in 1900, and today being 79 years (CDC, 2014g). Now, while a baby born in Japan has a life expectancy of 84 years, the one born in Sierra Leone has a life expectancy of 46 years [7].

\section{Structural Changes}

Process of aging causes many biological, physical, psychological and medical changes within the elderly people. All these changes continue to be painful in various types including Alzheimer's and Dementia disorders. Some elderly people with Alzheimer's disease even forget their home addresses, their spouses' names, their own names etc. When leaving home, they cannot easily be back due to their mental health. Such a situation will be qualitatively and quantitatively worse in the years to come when they will grow more in number, and when more sociological changes will appear.

\section{Method of Research}

Methodology used in the present abridged article is of qualitative type. In that, various paradigms have been used for fact finding. The method applied in the present study, searched the needs in their natural settings. In fact finding for the research, the researcher engaged in a careful collection of data in a thoughtful manner, and what was in need and relevant, was analyzed. The documentary research applied for data collection includes printed and written materials which were widely regarded. The research being a qualitative library type, in that, the researcher had to refer to relevant and related sources; such as books, journals and statistical resources in a thorough way to access the needful information. As a naturalistic inquiry, the researcher could almost reach an in-depth understanding of some social phenomena which could help other social researchers and thinkers in the future as well.

\section{Sustenance of Healthy Mentality}

Sustaining a healthy Mentality is only possible if housing, food, household budget and education are provided. Under such an atmosphere social management could suitably be fulfilled [8]. This is also worth mentioning that the developed countries also reach economic health through variables such as safety, discipline and social accounting. The system of healthy Mentality could only be applicable under the conditions/standards of enough food and housing for all classes of people [9]. To attain the pre-planned objectives, enough investment in terms of place and time need to be applied. Many of the developing countries of the world have put into practice the necessary infrastructural indices so that they could reach the status of a healthy aging.

Atchley's theory illustrates that individuals in later life make adaptions, to enable them to gain a sense of continuity between the past and the present, and the theory implies that, this states helps to contribute to well-being in later life [10].

\section{Healthy Economy Vs Development}

Social, environmental and cultural factors all have an effective impact on a healthy economy, and integration of all could lead to a healthy society and mental health. Similarly, healthy economy could be counted as a guardian of development in general. Hence, economic plans, and further economic growth, and also a condition in which social capital is crytstallized, each as agents of healthy economy, play role. In the meantime, creation of a safe environment will be attainable in a society, through the preservation of health in a society [11]. Similarly, accessing appropriate cultural backgrounds, or in other words, reformation of cultural and artistic structure in a society plays as the guardian of health system.

\section{Vulnerability of Environment}

Increasing number of urban areas in Africa, Asia and Latin America, as a result of their rapid population growth, poor and weak social accounting, and their deteriorating socio-economic conditions, are encountering increasing vulnerabilities. These countries have been facing extensive migrations. Such interactions have had social, economic and cultural impacts on these societies including destructive, negative environmental and social pollution, in addition to food shortage. As compared with developed societies, they are prone to a large number of vulnerabilities. The objective outcome of which has 
influenced different social groups of people in various aspects. Therefore, social accounting of environment will bridge the societies to socio-mental health. Such countries are constantly facing migrants to cities who encounter shortage of necessary goods, services and food. Therefore, applied sociology through social accounting must be used to study the present and future generations with a focus on their needs [12].

\section{Conclusion}

Mental health disorders though diagnosed by mental health professionals, yet they need to be studied from sociological point of view as well since many mental health disorders have roots in social status of individuals, their functions, their social environment, their social protection etc. Common mental disorders including depression have roots in social order. Suffering, disability, and discrimination are widely associated with mental disorders. However, rise and fall of nervous system widely impact mental health. Objectives of the study can be manifold, but can typically be described in terms of social and environmental desirability and sustainability, food accessibility etc. [13]

\section{Reference}

1. Abeles, R. P., and M. W. Riley., (1987), "Longevity, Social Structure, and Cognitive Aging". In C. Schooler and Social Structure over the Life Course. Norwood, NJ: Albex.

2. Atchley, R.C., (2000), Social Forces and Aging: An Introduction to Social Gerontology, 9th ed. Belmont, CA: Wadsworth.

3. Riley, M.W., Foner and J.Waring, (1988). "Sociology of Age." In N.J. Smelser, ed., Handbook of Sociology. Newbury Park, CA: Sage.
4. World Population Data Sheet (WPDS), 2018, Population Reference Bureau, New York, United Nations.

5. Mellisa, B., et al., (2017) Fertility Law and Ethics, Fertility Today, USA.

6. Sheykhi, Mohammad T., (2001) Economic and Social Demography, 2nd Edition, Shekate Sahamie Enteshar, Tehran, Iran.

7. World Health Organization (WHO), (2014b), "World Health Statistics, 2014." Retrieved 12/14

8. Hobbs, M., (2002) Growing a Healthy Environment, Bulletin on Healthy Economy, New Zealand,

9. Charles, W., 12 (2008) Healthy Economy Requires Moral Restraints, Newsweek,

10. Bowling, Ann., (2005). Ageing Well: Quality of Life in Old Age, Open University Press.

11. Ruhm, C. J., NBER., Working Paper, University of North Carolina, Bulletin on Aging and Health, Number 12102,12006.

12. Sheykhi, Mohammad T., (2016) Sociology of Environment, Harir Publications, Tehran, Iran.

13. Retrieved, 2019, Social Accounting

14. Centers for Disease Control and and Prevention (CDC), (2014g). "Mortality in the United States, NCHS Data Brief, No. 168, October. Retrieved 12/14, from

15. Stuart-Hamilton, Ian, The psychology of Ageing: An Introduction, London: Jessica Kingsly Publishers.

16. Centers for Disease Control and Prevention (CDC), (2014g). "Mortality in the United States, NCHS Data Brief, No. 168, October. Retrieved 12/14. (c) (P) This work is licensed under Creative Commons Attribution 4.0 License

\section{To Submit Your Article Click Here: Submit Article}

DOI: $10.31579 / 2693-4779 / 002$
Ready to submit your research? Choose Auctores and benefit from:

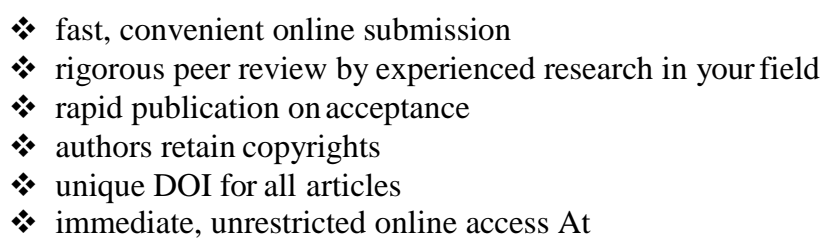

Auctores, research is always in progress.

Learn more www.auctoresonline.org/journals/clinical-research-andclinical-trials 